\title{
Rhesus Monkey Lymphoma
}

National Cancer Institute

\section{Source}

National Cancer Institute. Rhesus Monkey Lymphoma. NCI Thesaurus. Code C134783.

Lymphoma that occurs in a rhesus monkey. 